\title{
TWO NEW SPECIES OF AMBLYCERUS THUNBERG \\ FROM BRAZIL (COLEOPTERA, BRUCHIDAE) ${ }^{1}$
}

\section{Cibele S. Ribeiro-Costa ${ }^{2}$}

\begin{abstract}
Amblycerus kingsolveri, sp. n. from Amazonas, Brazil and A. marinonii, sp. n. from Goiás, Brazil, are described and illustrated.

Key words. Taxonomy, seed beetles, Amblycerus spp. n., Brazil
\end{abstract}

The following two new species of Amblycerus Thunberg, 1815 are closely related and both will be the basis to establish another species group in the genus. As in the latest papers on Amblycerus (KINGSOLVER, 1991; RIBEIRO-COSTA \& KINGSOLVER, 1993; RIBEIRO-COSTA \& KINGSOLVER, in press), this paper also describes new species, making names available for future revision and taxonomic analysis.

\section{Amblycerus kingsolveri, sp. n. \\ Figs 1-6}

The dimensions of the holotype are: pronotal length $1.74 \mathrm{~mm}$; width $2.92 \mathrm{~mm}$. Elytral length $5.33 \mathrm{~mm}$; width $4.08 \mathrm{~mm}$.

Range of dimensions in type series are: pronotal length $1.26-1.74 \mathrm{~mm}$; width $2.08-2.92 \mathrm{~mm}$. Elytral length $3.84-5.33 \mathrm{~mm}$; width $2.90-4.08 \mathrm{~mm}$.

Integument. Reddish yellow except: eyes and from third to eleventh antennal segments, dark red or black; clypeus, mandibles and legs sometimes gently darker yellow.

Vestiture. Body clothed with very fine light yellow hairs with slightly golden sheen (Fig. 1).

Body elliptical (Fig. 1). Vertex and frons micropunctate; clypeus except in a granulose apical narrow band, slightly more coarsely punctate; labrum with a few basal punctures. Frons strongly convex, frontal carina evanescent in lower half. Mesal margin of eye with fine carina and umbilicate punctures; eye coarsely faceted, strongly protruding laterally; ocular sinus $1 / 4$ length of eye; ocular index 5:0; postocular lobe very narrow. Antenna serrate from fourth to tenth segments, all perceptibly longer than wide; terminal segment elliptical (Fig. 2). Pronotum (Fig. 1) trapezoidal, lateral margins slightly arcuate; disk moderately convex; basal lobe broadly angulate, not sulcate; surface evenly densely punctulate

1) Contribuição número 762 do Departamento de Zoologia, Universidade Federal do Paraná.

2) Departamento de Zoologia, Universidade Federal do Paraná, Caixa Postal 19020, 81531-970 Curitiba, Paraná, Brasil. 

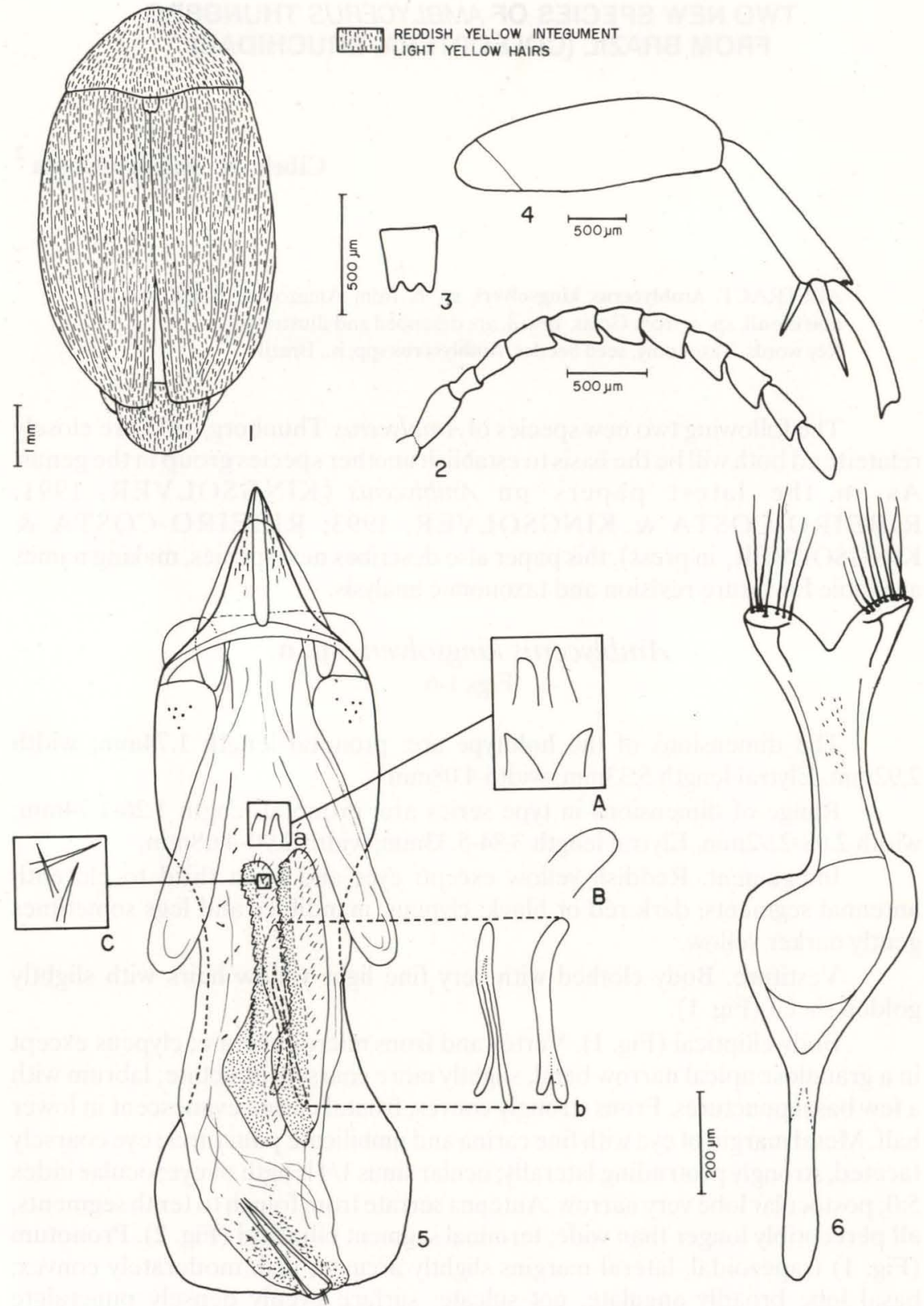

Figs 1-6. Amblycerus kingsolveri, sp.n. (1) dorsal habitus; (2) antenna; (3) scutellum; (4) hind trochanter, femur, tibia and first tarsal segment; (5) male genitalia, median lobe: (a) basal sclerites, (A) intraspecific variations of basal sclerites enlarged, (b) lateral view of unpaired median sclerite, (B) lateral view of apex enlarged, (C) spiculae enlarged; (6) male genitalia, tegmen. 
throughout, lateral one-third of disk on either side also coarsely punctate; a fine submarginal dorsal and a submarginal ventral sulcus from base to middle of lateral margin, submarginal dorsal sulcus visible for nearly entire basal margin; cervical sulcus along lateral thirds of apical margin, hooked dorsad to cervical boss, this with two fine setae; posterior angle of pronotum with one seta. Prosternal process moderately or very narrow, not expanded beyond forecoxae; with sulcate lateral margins. Forecoxae conspicuously lower than median coxae in ventral view. Scutellum 1.3 times as long as wide, with trilobed apex (Fig.3). Elytra 1.3 times as long as wide, somewhat depressed medially; sutural interstices gently convex; all striae strongly impressed, free apically; strial punctures fine; elytral apices subtruncated. Mesosternum truncated apically. Metepisternum evenly punctulate, lacking striate file; metepisternal sulcus forming a right angle with the parasutural sulcus, metepisternal sulcus not reaching dorsal margin and parasutural sulcus reaching middle length of metepisternum. Metasternum between middle coxae not bulging; postmesocoxal sulci meeting mesally at obtuse angle, then extending laterally and connecting to parasutural sulcus, the latter extending beyond middle length of metasternum. Face of hind coxa in distal two-thirds and along posterior border of proximal one-third, setose and densely punctulate; many scattered, moderately coarser punctures on distal two thirds; proximal one-third glabrous in part and with coarser punctures near trochanteral insertion; anterior margin slightly elevated and glabrous. Hind femur slender, 2.7 times as long as wide (Fig. 4); ventral face slightly sulcate from middle to distal portion; mesoventral carina complete and lacking blunt, angulate process near apex; lateroventral carina incomplete, along middle to distal portion. Ventral face of hind tibia slightly convex, with inconspicuous rows of punctures and short, stiff setae on each margin; inner distal two-thirds without tumidity; apex (Fig. 4) with short coronal denticles. Mesal tibial spur 1.9 as long as the lateral spur and 2.5 as long as the first hind tarsal segment (Fig. 4). Pygidium moderately declivous. Fifth visible abdominal sternum slightly emarginate in male. Female not known.

Male terminalia (Figs 5, 6). Eighth tergite truncated.Median lobe (Fig. 5) with ventral valve acute apically, lateral margins moderately incurvate, base broad; dorsal valve subtriangular, lateral margins slightly convex, apex rounded. Internal sac armature (Fig. 5) consisting of two basal spine-shaped straight sclerites, 2.8 times as long as wide (Fig. 5a) or as in figure 5A; two long, laminar and median sclerites, each one slightly angulate in basal one-fourth and with a row of marginal denticles along apical three fourths, and armed on the reverse face with spiculae (Fig. 5C); unpaired, median wishbone-shaped sclerite, 0.6 as long as the length of the laminars, with slightly separate stems, moderately sinuate toward apex and with rounded apex in lateral view (Fig. 5b, B); apical sclerite with thin base and long stems. Membrane of internal sac with sparse spines on basal and median portions (Fig. 5). Lateral lobes moderately developed and expanded laterally (Fig. 6).

Holotype male. Brazil: Amazonas, Rio Tarumã Mirim, $2 \mathrm{Km}$ from Rio Negro, $03^{\circ} 02^{\prime} \mathrm{S}-06^{\circ} 17^{\prime} \mathrm{W} ; 30$ July 79 ; Adis, Erwin, Montgomery leg. One 
paratype male, Brazil: Amazonas, Manaus; 1941. Deposited in the Coleção de Entomologia Pe. J. S. Moure, Curitiba (DZUP).
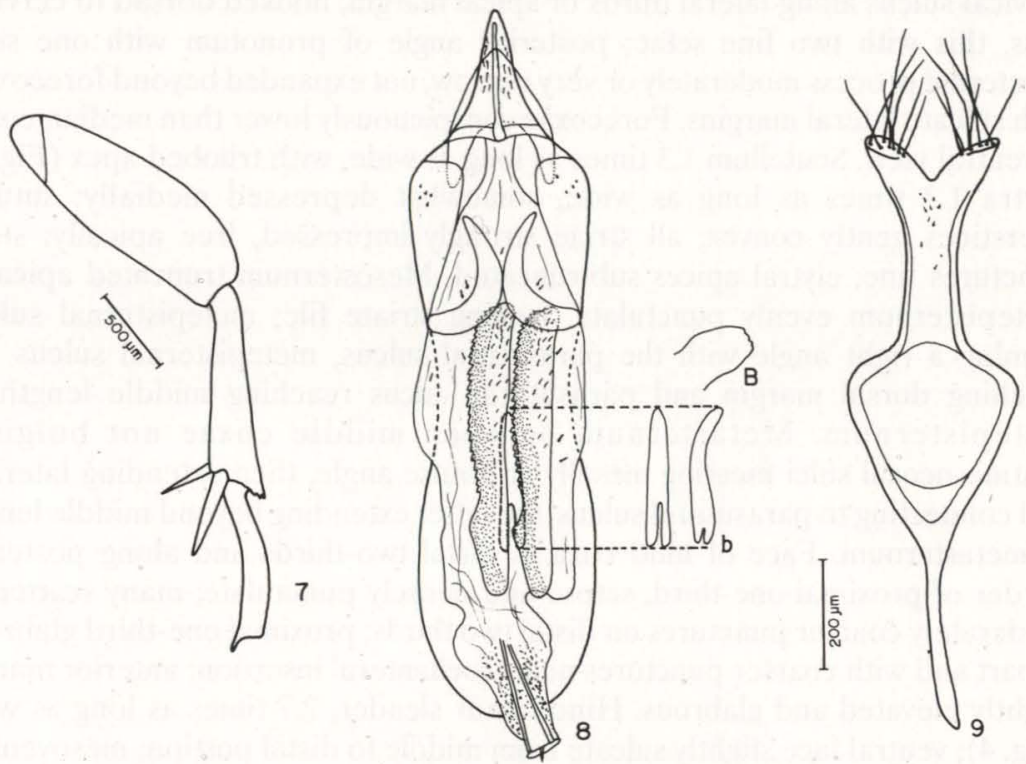

Figs 7-9. Amblycerus marinonii, sp.n. (7) hind trochanter, femur, tibia and first tarsal segment; (8) male genitalia, median lobe: (b) lateral view of unpaired median sclerite, (B) lateral view of apex enlarged; (9) male genitalia, tegmen.

Discussion. There is a close relationship between $A$. kingsolveri and $A$. marinonii, the next new species. The conspicuous external character to immediately recognize them is the integument colour (body reddish yellow except eyes and from third to eleventh antennal segments dark red to black in $A$. kingsolveri and uniformly dark red in $A$. marinonii). Another distinctive character is the basal spine-shaped pair of sclerites in the internal sac of male genitalia (straight in $A$. kingsolveri, strongly curvate in $A$. marinonii). Median laminar and wishbone-shaped sclerites are similar in both species, suggesting the close affinity.

Host plant unknown.

\section{Amblycerus marinonii, sp. $\mathbf{n}$.}

Figs 7-9

The description of $A$. marinonii is similar of $A$. kingsolveri except for the following characters:

The dimensions of the holotype are: pronotal length $1.24 \mathrm{~mm}$; width $2.00 \mathrm{~mm}$. Elytral length $3.60 \mathrm{~mm}$; width $2.52 \mathrm{~mm}$. 
Integument: Dark red.

The second and ninth, third and eighth, sixth and seventh striae nearly joined apically. Hind mesal tibial spur 1.7 as long as lateral spur and 2.8 as long as first tarsal segment (Fig. 7). Fifth visible abdominal sternum rounded in male. Female not known.

Male genitalia(Figs 8, 9). Dorsal valve of median lobe (Fig. 8) with straight lateral margins and acute apex. Internal sac armature (Fig. 8) consisting of two basal, spine-shaped, strongly curvate sclerites.

Holotype male. Brazil: Goiás, Dianópolis; 16-22.I.1962, J. Bechyné leg. Deposited in the Coleção de Entomologia Pe. J. S. Moure, Curitiba (DZUP).

Host plant unknown.

Etymology: These two new species are named for my friends and advisors Drs. John M. Kingsolver and Renato C. Marinoni who have helped me in the studies of Systematic and Numerical Taxonomy Analysis of Bruchidae.

\section{BIBLIOGRAPHIC REFERENCES}

KINGSOLVER, J.M. 1991. A new species of Amblycerus (Coleoptera: Bruchidae) from Central and South America, with notes on its biology. Proc. ent. Soc. Wash. 93 (2):433-436.

RIBEIRO-COSTA, C.S. \& J.M. KINGSOLVER. 1993. A new species of Amblycerus Thunberg, 1815 (Coleoptera: Bruchidae) and a lectotype designation. Insecta Mundi 6 (3-4): 183-187.

- (in press). Amblycerus teutoniensis, a new species of seed beetle (Coleoptera: Bruchidae). Ent. News.

Recebido em 02. XI.1992; aceito em 07.Vl.1993. 